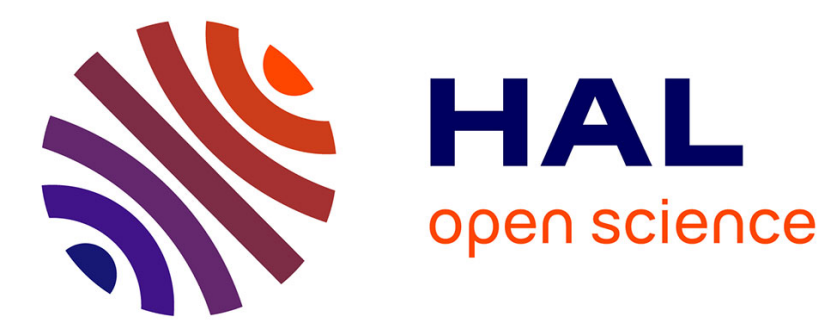

\title{
UC_ $x$ target design for the SPIRAL 2 project and the ALTO project
}

\author{
O. Bajeat, F. Azaiez, C. Bourgeois, M. Cheikh Mahmed, H. Croizet, M. \\ Ducourtieux, S. Essabaa, R. Sifi, S. Franchoo, F. Ibrahim, et al.
}

\section{- To cite this version:}

O. Bajeat, F. Azaiez, C. Bourgeois, M. Cheikh Mahmed, H. Croizet, et al.. UC_ $x$ target design for the SPIRAL 2 project and the ALTO project. EXON 2004, International Symposium on Exotic Nuclei, Jul 2004, Peterhof, Russia. pp.630-635. in2p3-00023293

\section{HAL Id: in2p3-00023293 https://hal.in2p3.fr/in2p3-00023293}

Submitted on 1 Dec 2004

HAL is a multi-disciplinary open access archive for the deposit and dissemination of scientific research documents, whether they are published or not. The documents may come from teaching and research institutions in France or abroad, or from public or private research centers.
L'archive ouverte pluridisciplinaire HAL, est destinée au dépôt et à la diffusion de documents scientifiques de niveau recherche, publiés ou non, émanant des établissements d'enseignement et de recherche français ou étrangers, des laboratoires publics ou privés. 


\title{
UC $_{X}$ TARGET DESIGN FOR THE SPIRAL 2 PROJECT AND THE ALTO PROJECT
}

O. BAJEAT* ${ }^{*}$ F. AZAIEZ, C. BOURGEOIS, M. CHEIKH MAHMED, H. CROIZET, M. DUCOURTIEUX, S. ESSABAA, R. SIFI, S. FRANCHOO, F. IBRAHIM, C. LAU, F. LEBLANC, H. LEFORT, M. MIREA, C. PHAN VIET, JC. POTIER, B. ROUSSIERE, J. SAUVAGE, D. VERNEY, F. POUGHEON

Institut de Physique Nucléaire, 91406 Orsay, France

G. GAUBERT, P. JARDIN, Y. HUGUET, N. LECESNE, P. LECOMTE, R. LEROY, F. PELLEMOINE, M.G. SAINT-LAURENT

GANIL, Bd H. Becquerel 14076 Caen cedex 5, France

F. NIZERY, D. RIDIKAS

DAPNIA, CEA Saclay, 91191 Gif sur Yvette, France

\author{
R.V. RIBAS
}

Instituto de Fisica, Universidade de Sao Paolo, SP ,CP. 66318, 05315-970, Brazil

\begin{abstract}
Two ways of production of radioactive beams using uranium carbide targets are taken into consideration: fission induced by fast neutrons and by bremsstrahlung radiation. For the SPIRAL 2 project, the fission of ${ }^{238} \mathrm{U}$ in uranium carbide target will be induced by a neutron flow created by bombarding a carbon converter with a $40 \mathrm{MeV}$ high intensity deuteron beam. Calculations and design of the target in order to reach $10^{13}$ fissions/s with good release time have been done. The second way is the photofission using an electron beam. In 2005 the ALTO project (Accélérateur Linéaire Auprès du Tandem d’Orsay) will give a $50 \mathrm{MeV} / 10 \mu \mathrm{A}$ electron beam. This facility will allow more than $10^{11}$ fissions/s. In this case, the electron beam hits the target without converter. Calculations realised in order to estimate the production are used to choose the best target shape. For the two cases some R \& D on targets to improve release is described.
\end{abstract}

\section{The UCx targets}

For both projects: Spiral 2 with fast neutrons and Alto with electrons same kinds of targets will be used. Targets are based on the Isolde method [1]. Such a type of thick target is an assembly of disks (thickness about $1 \mathrm{~mm}$ ) composed of a mixing of uranium carbide and graphite. These pellets are obtained by compressing a mix of uranium oxide and graphite powders. The carbonation is made by heating the pellets up to $2000{ }^{\circ} \mathrm{C}$ under vacuum to make the reaction:

\footnotetext{
* Corresponding author: bajeat@ipno.in2p3.fr
} 
$\mathrm{UO} 2+6 \mathrm{C} \rightarrow \mathrm{UC} 2+2 \mathrm{C}+2 \mathrm{CO} \uparrow$ or $\mathrm{UO} 2+6 \mathrm{C} \rightarrow \mathrm{UC}+3 \mathrm{C}+2 \mathrm{CO} \uparrow$. The graphite allows limiting the carbide grain size for minimizing diffusion paths. The figure 1 shows the structure of a target. During irradiation, targets are heated up to $2200^{\circ} \mathrm{C}$.

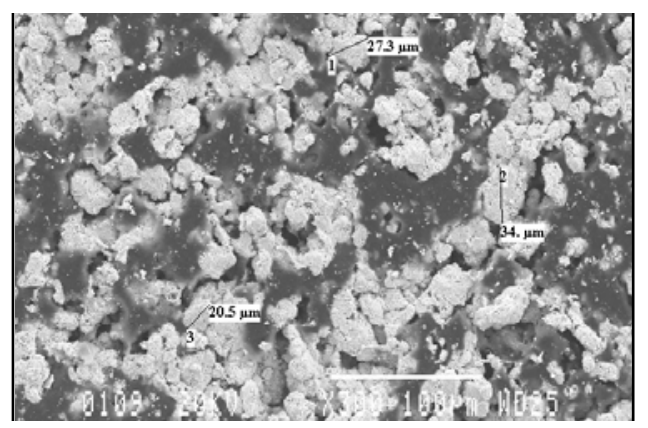

Fig. 1: structure of an UCx target by Scanning Electron Microscopy. The graphite appears in black, the uranium carbide $\mathrm{UC}$ and $\mathrm{UC}_{2}$ in white. The uranium carbide grain size is about 20 to $30 \mu \mathrm{m}$.

\section{The Spiral 2 target}

For the SPIRAL 2 project the specification is to reach $10^{13}$ fissions/s in the case of UCx target using a $40 \mathrm{MeV} / 5 \mathrm{~mA}$ deuteron beam with a rotating carbon converter [2]. The production of a target irradiated by fast neutrons is estimated using the FICNER code [3]. Thanks to this code one can see the effect of geometrical parameters onto the production. The figure 2 illustrates the importance to put the target as close as possible to the converter.

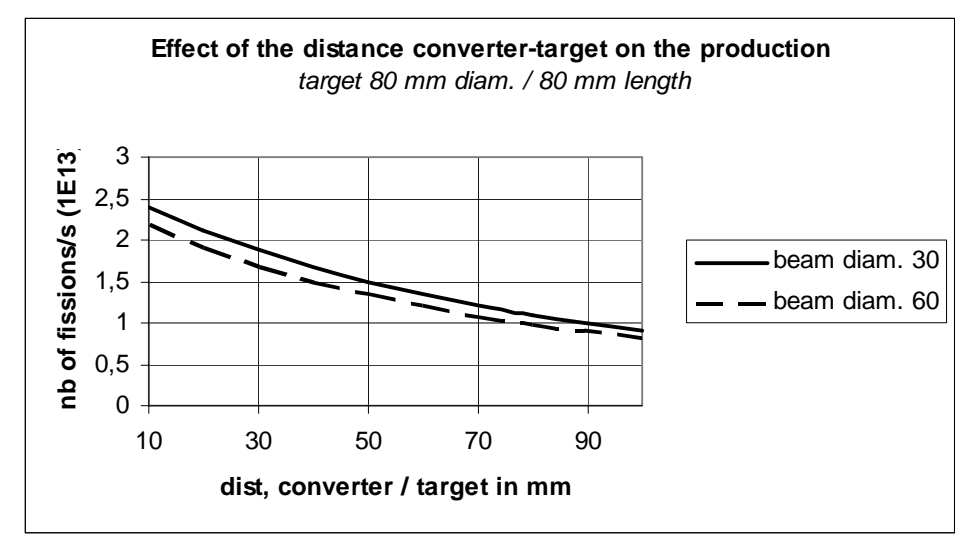

Fig. 2. Effect of the converter-target distance on the production for 2 beam sizes (diameter $30 \mathrm{~mm}$ and $60 \mathrm{~mm}$ ). 
With this calculation code it has also been demonstrated that a conical target would not be better for the production than a cylindrical one with the same volume. For the Spiral 2 project we plan to make a target diameter $80-\mathrm{mm}$, length $80-\mathrm{mm}$, at about $40 \mathrm{~mm}$ from the entrance of the converter (figure 3).

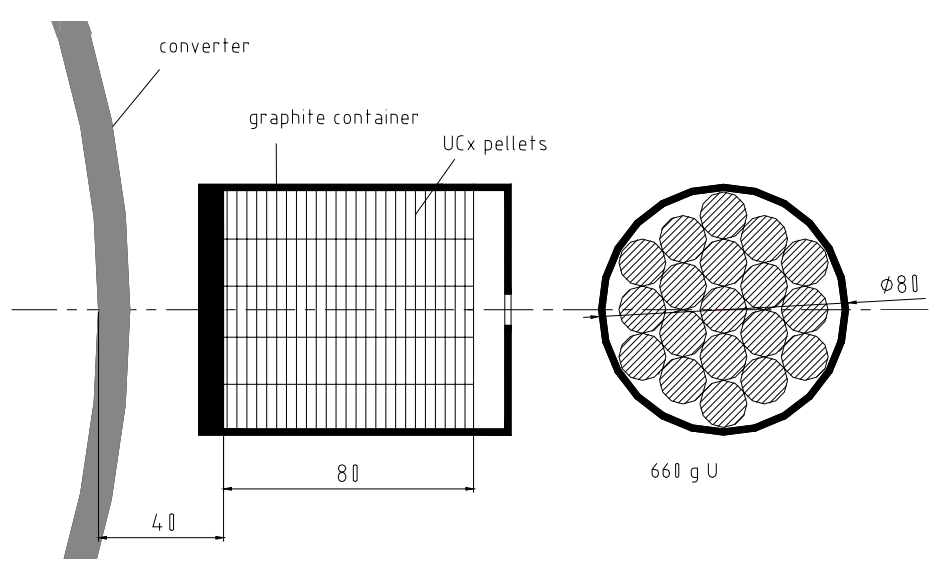

Figure 3. The SPIRAL 2 target: 19 series of about 60 pellets diameter $15 \mathrm{~mm}$, thickness $1 \mathrm{~mm}$, spacing about $0.3 \mathrm{~mm}$ between each pellet.

The target has to work at a temperature higher than $2000{ }^{\circ} \mathrm{C}$ in order to allow an efficient release of the produced radioactive elements. The power deposited inside the target by the fission reactions is about $500 \mathrm{~W}$ for $1.610^{13} \mathrm{f} / \mathrm{s}$. Then, an extra heating must be added in order to reach convenient temperatures. A tantalum oven prototype is under construction. The pellets will be in a graphite container surrounded by a tantalum foil to avoid reaction between carbon and the oven. The main difficulty will be to obtain a homogeneous temperature of the target for a long duration (3 months). Moreover the transfer tube between the target and the ion source has to be heated at $2000^{\circ} \mathrm{C}$ too for the ionization of non volatile nuclei.

\section{The Alto target}

For this project the goal is to reach $10^{11}$ fissions/s using a $50 \mathrm{MeV} / 10 \mu \mathrm{A}$ electron beam to produce radioactive beams in the PARRNE separator already existing at IPN Orsay [4]. The production of the target is estimated using the FICEL code [5]. Due to the absorption of photons the production does not increase proportionally with the target density. The case of a conical shape has 
been also studied. The table 1 shows that a conical target 3 times larger would produce only $30 \%$ more fission events than the cylindrical one.

\begin{tabular}{|c|c|c|c|c|}
\hline $\begin{array}{c}1^{\text {st }} \text { diameter } \\
\mathrm{Mm}\end{array}$ & $\begin{array}{c}2^{\text {nd }} \text { diameter } \\
\mathrm{mm}\end{array}$ & $\begin{array}{c}\text { Length } \\
\mathrm{mm}\end{array}$ & $\begin{array}{c}\text { Volume } \\
\mathrm{cm}^{3}\end{array}$ & $\begin{array}{c}\text { Nb fission/s } \\
\text { for } 10 \mu \mathrm{A}\end{array}$ \\
\hline 14 & 14 & 100 & 15 & $1.010^{11}$ \\
\hline 14 & 34 & 100 & 47 & $1.310^{11}$ \\
\hline \multicolumn{4}{|c}{ Table 1. Comparison of a cylindrical and a conical target for }
\end{tabular}

photofission (target density $=2.4 \mathrm{~g} / \mathrm{cm}^{3}$ )

For ALTO project we'll use an assembly of about 90 pellets of $14 \mathrm{~mm}$ diameter, $1 \mathrm{~mm}$ thickness and within a small spacing between each pellet. For such a target, $350 \mathrm{~W}$ of the $500 \mathrm{~W}$ incident beam will be absorbed in the target, $150 \mathrm{~W}$ being re-emitted out of the target as photon radiation.

\subsection{The case of a converter}

The production in the target using a tungsten converter has been studied. In this case a part of the fission events is due to the photons emitted from the converter. Another part is due to bremsstrahlung radiations produced in the target by the electrons which hit the target if the converter thickness is lower than the electron range in the tungsten.

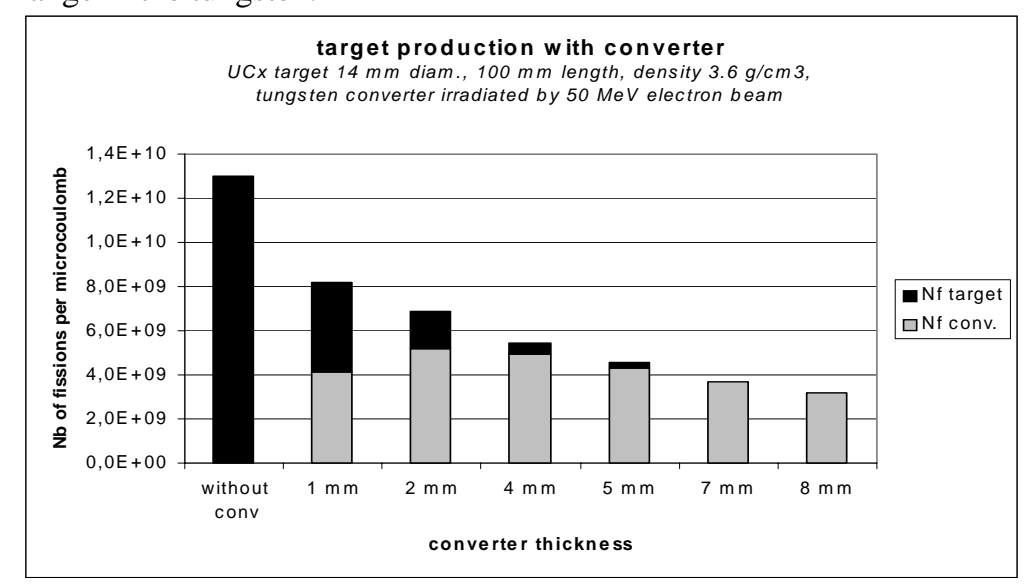

Figure 3. Fission produced in the target with various converter thicknesses. In black: fission induced by photons produced in the target. In gray: fission induced by photons produced in the converter. The converter is in direct contact with the target.

These results proved the production is better without converter. Nevertheless, a converter could be useful to reduce the energy deposited in the target. In fact if the converter thickness is equal to the range of electrons, no 
electrons will hit the target and only the energy due to photon absorption will be deposited in the target. The results given in the table 2 show that the converter would reduce the production by a factor 5 while the energy deposited would be reduced by a factor 10 .

Table 2. Production and energy deposited in the target without converter and with a $10 \mathrm{~mm}$ tungsten converter.

\begin{tabular}{|l|c|c|}
\hline & $\begin{array}{c}\text { Nb of fission per } \\
\mu \mathrm{C}\end{array}$ & $\begin{array}{c}\text { Energy deposition } \\
\text { in } \mathrm{MeV}\end{array}$ \\
\hline Without converter & $1.310^{10}$ & 35 \\
\hline Converter W $10 \mathrm{~mm}$ & $0.2610^{10}$ & 3.4 \\
\hline
\end{tabular}

\subsection{Gamma dose rate}

Knowing the angular and energy distribution of photons $\mathrm{N}(\mathrm{E}, \theta)$ emitted out of the target, the dose rate is given by :

$$
D(\theta)=\int_{E} \frac{N(E, \theta)}{F(E)} d E
$$

$\mathrm{F}(\mathrm{E})$ being the photon conversion factor. The figure 4 confirms that dose rate is very high in forwarded direction, but even in other directions some important shielding becomes necessary.

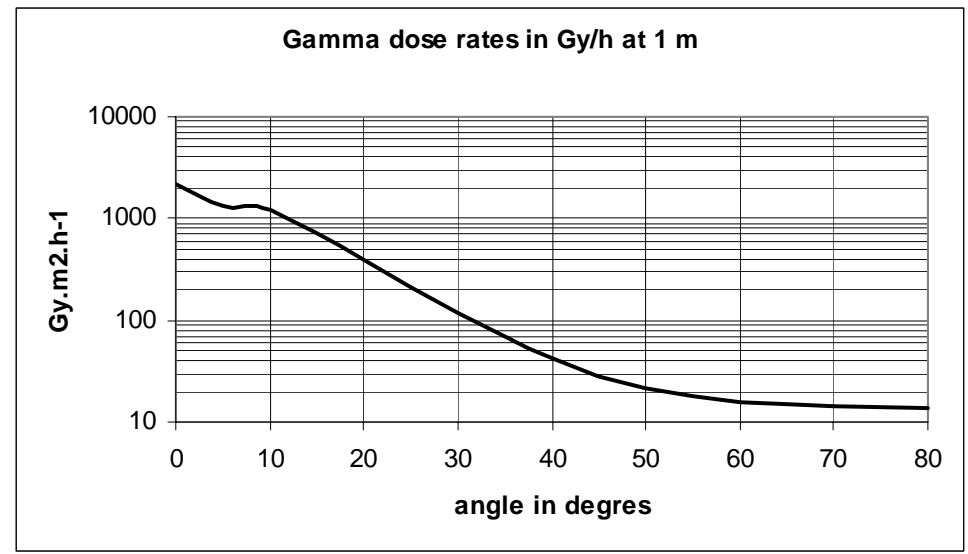

Figure 4: gamma dose rate by an UCx target diam. $14 \mathrm{~mm}$, length $150 \mathrm{~mm}$, density $3.6 \mathrm{~g} / \mathrm{cm}^{3}$ irradiated by a $50 \mathrm{MeV} / 10 \mu \mathrm{A}$ electron beam. 


\section{The release times (Spiral 2 and Alto)}

Some effusion calculations using the Monte-Carlo method have demonstrated that spacing between the pellets can decrease the mean number of collisions of radioactive atoms to get the entrance of the ion source. But in the same time the production will be lower due to the lower effective density of the target. A new kind of target made by an assembly of disks with 3 bumps thickness $0.3 \mathrm{~mm}$ has been realized as presented on the figure 4 . This new target has been tested on line using the PARRNE set up $(25 \mathrm{MeV} / 1 \mu \mathrm{A}$ deuteron beam on a carbon converter).

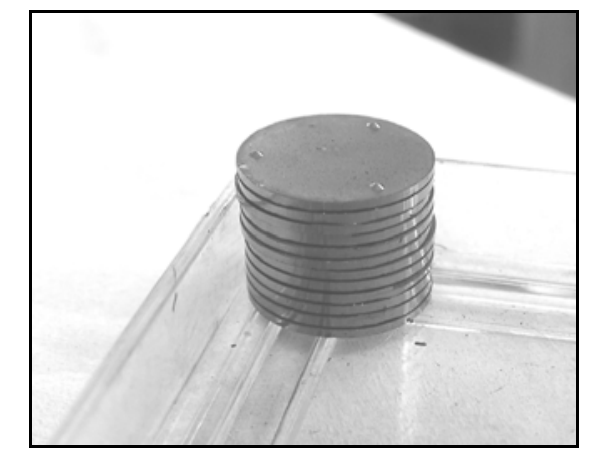

Figure 4: view of a piece of the target with $0.3 \mathrm{~mm}$ bumps. The target is constituted of 123 pellets diameter $15 \mathrm{~mm}$. Each pellets thickness is about $1 \mathrm{~mm}(0.7 \mathrm{~mm}+0.3 \mathrm{~mm})$

Release time measurements on ${ }^{132} \mathrm{Sn}$ and ${ }^{139} \mathrm{Xe}$ have been performed using this new $\mathrm{UC}_{\mathrm{x}}$ target. Assuming that the predominant release mechanism is effusion in case of tin and diffusion in case of xenon, the measurement and the analysis have been carried out as indicated in refs. [6,7]. Preliminary results indicate $T_{R}$ $\approx 40 \mathrm{~s}$ for tin and $\mathrm{T}_{\mathrm{R}} \approx 20 \mathrm{~s}$ for xenon. Previous measurements performed with the same target+ion-source temperature conditions $\left(\mathrm{T}_{\text {target }}=2080^{\circ} \mathrm{C}\right.$ and $\mathrm{T}_{\text {line }}=$ $2100^{\circ} \mathrm{C}$ ) but using a target without bumps had led to $T_{R}=55 \mathrm{~s}$ for tin and $\mathrm{T}_{\mathrm{R}}=$ $21 \mathrm{~s}$ for xenon. Consequently, this seems to confirm that with the new target the release time remains the same for diffusion but decreases for effusion.

\section{References}

1. H.L. Ravn et al. Nucl. Instr. And Method B 26 (1987) 183.

2. R. Anne. Technical status of Spiral 2. These proceedings.

3. M. Mirea et al. Modeling a neutron rich nuclei source. European Physical Journal A 11, 2001, pp. 59-78.

4. F. Ibrahim. The ALTO project at IPN Orsay. These proceedings. 
5. M. Mirea et al. Exploratory analysis of a neutron-rich nuclei source based on photo-fission, NIM B 201, 2003, pp. 433-448.

6. B. Roussière et al. Release properties of UCx and molten U targets. NIM B 194, 2002, pp. 151-163.

7. C. Lau et al., NIMB204 (2003)246. 